\title{
Chapter 6 \\ Rational Goals in Engineering Design: The Venice Dams
}

\author{
Karin Edvardsson Björnberg
}

\section{Introduction}

The rationality of scientific goals has been a much discussed topic in philosophy of science since the publication of Larry Laudan's Science and Values in 1984 (e.g. Iranzo 1995; Baumslag 1998; Cíntora 1999). Until now, significantly less attention has been paid to the rationality of engineering goals, although exceptions exist (e.g. Hughes 2009; Kroes et al. 2009; de Vries 2009). As goals have a central action-directing and coordinating function in the engineering design process, there seems to be a gap in the research. Engineering projects usually start with an identified customer need or desire that is transformed into a set of functional requirements and design specifications for the development of the artefact. These needs, requirements and specifications serve as criteria for the development, testing, evaluation and readjustment of different design solutions. Negotiating and trading off different and often competing requirements is therefore an essential part of the engineering design process.

As goals (understood as customer needs, functional requirements and design specifications) have a central guiding role in the engineering design process, there is a need to investigate what normative criteria the goals should meet to be successful: What is a good (i.e. functional or rational) engineering goal? ${ }^{1}$ In this chapter, a set of criteria developed by Edvardsson and Hansson (2005) and Edvardsson Björnberg (2009) as part of an evaluative framework for public policy goals is analysed using

\footnotetext{
${ }^{1}$ Throughout this chapter, the term "rationality" is given a wide interpretation. The term "rational engineering goal" is used to denote a goal that fulfils the typical function of goals to direct action in order to facilitate goal achievement. Readers who prefer a more restricted usage of the term "rationality" may instead use the terms "functional engineering goals" or "successful engineering goals" when references are made to "rational engineering goals."
}

K.E. Björnberg $(\varangle)$

Royal Institute of Technology, Stockholm, Sweden

e-mail: karine@kth.se 
the large-scale engineering project of the Venice Dams (henceforth, the MOSE system) as an empirical basis. The fundamental assumption of the analysis is that goals that satisfy the set criteria fulfil their typical function as goals; they have the capacity to direct and coordinate action in a way that facilitates goal achievement (i.e. "achievement-inducing" goals).

Four criteria are particularly useful as analytical tools in the context of engineering design: precision, evaluability, approachability and consistency (see also Hughes 2009, p. 393). ${ }^{2}$ Precision means that it is clear what the designed artefact should be able to achieve in terms of outer (customer-environment) and inner (device-environment) functions. Evaluability means that it is possible to establish the extent to which customer needs, functional requirements and design specifications have been met. Approachability means that it is feasible to come reasonably close to satisfying customer needs, functional requirements and design specifications. Consistency, or coherence, means that customer needs, functional requirements and design specifications can be met simultaneously; hence, that there are no significant conflicts among the requirements. The normative strength of the goal criteria varies depending on which part of the engineering design process is under consideration. As a general rule, the "further down" in the transformation process from customer needs to design specifications, the more important it is that the goals engineers work with satisfy the identified criteria.

Prior to the philosophical analysis, the role of goals in engineering design is discussed. The function and design of the MOSE system are also described in greater detail. This is done in Sects. 2 and 3, respectively. In Sects. 4, 5, 6 and 7, the four goal criteria are analysed using examples from the MOSE design process. Section 8 contains some concluding remarks. Contrary to the idea, embraced by many philosophers, that goals unlike means cannot be assessed in terms of rationality, this chapter concludes that engineering goals can indeed be evaluated on the basis of such considerations.

\section{The Function of Engineering Goals}

Engineering projects start with an identified customer need or problem and end with the production of an artefact or artefact-based service that satisfies this need or solves the problem. ${ }^{3}$ Between the problem-identification stage and the production stage, a variety of activities take place. Some of these activities are referred to as

\footnotetext{
${ }^{2}$ Edvardsson and Hansson (2005) indicate that a goal should ideally also satisfy the criterion of motivity, that is, it should have the capacity to motivate action that facilitates goal achievement. This criterion is not discussed at any length in this chapter because it has a subordinate role in engineering design. Engineers work professionally and are therefore committed by external forces to act in ways that further goal achievement; hence, the motivation to do so is not triggered by the goals themselves.

${ }^{3}$ The fact that engineering projects start with an established customer need does not necessarily mean that an actual customer has expressed this need. Sometimes, engineering design projects proceed from the engineers' own estimations of what customers (or the market) desire or can be made to desire (de Vries 2009, p. 494).
} 
engineering design. The Accreditation Board for Engineering and Technology (ABET) defines engineering design as:

[t] he process of devising a system, component, or process to meet desired needs. It is a decision-making process (often iterative), in which the basic sciences and mathematics, and the engineering sciences are applied to convert resources optimally to meet these stated needs. ${ }^{4}$

The outcome of the engineering design process is a "use plan", or description, of a technical artefact that contains everything that must be known in order to manufacture that artefact (Kroes 2009, p. 513). The use plan can be supplemented with a prototype that demonstrates the effectiveness of the plan. As there is wide variety in engineering design practice, there are many kinds of artefacts, design problems and designer competencies. However, common to all design practices is that they are decision-making activities (Kroes et al. 2009). The engineering design process essentially proceeds through a large number of decisions: how many design options to generate, which options to develop further and which to abandon, how to make trade-offs between conflicting design requirements, what criteria to use in the evaluation of design solutions, etc.

The starting point of most design projects is an identified customer need. ${ }^{5}$ In the engineering design process, customer needs are translated, or transformed, into functional requirements (de Vries 2009). Functional requirements describe what the artefact must be able to do in order to satisfy the identified customer need. For example, for a flood barrier, the functional requirements could be capability of safeguarding from tides up to a certain level, capability of letting commercial and rescue vessels pass through the barrier while in operation and capability of being fully raised within a certain time from a received warning. Functional requirements are largely customer oriented and say little about the internal structure of the artefact, for example, about its geometrical, physical or chemical properties (Kroes 2009, p. 524).

Beside functional requirements, there are many other concerns to be addressed in the engineering design process: technical, environmental, economic, recreational, safety, aesthetic, etc. To take a simple example, a flood barrier should not only be able to safeguard the coast from flooding; the barrier should also be able to do so without causing damage to the environment and without jeopardising safety and recreational values. In the engineering design process, these concerns are often expressed through constraints on how the artefact should be designed and implemented. Some constraints are formal, that is, written out in regulations, engineering codes, contracts and other documents, whereas others are informal or only explicitly articulated when challenged (Bucciarelli 1994, p. 131). Some constraints are negotiable within limits, and others

\footnotetext{
${ }^{4}$ Criterion 5(b), ABET Criteria for Accrediting Engineering Programs 2009-2010, www.abet.org (accessed 10 April 2010).

${ }^{5}$ The customer can, for example, be an individual or a group of individuals, a public or private organisation, a company, the general public or the market. In large-scale engineering projects, such as flood barrier construction, the customer is often a public or semiprivate organisation that is formally authorised to represent a particular community or the general public.
} 

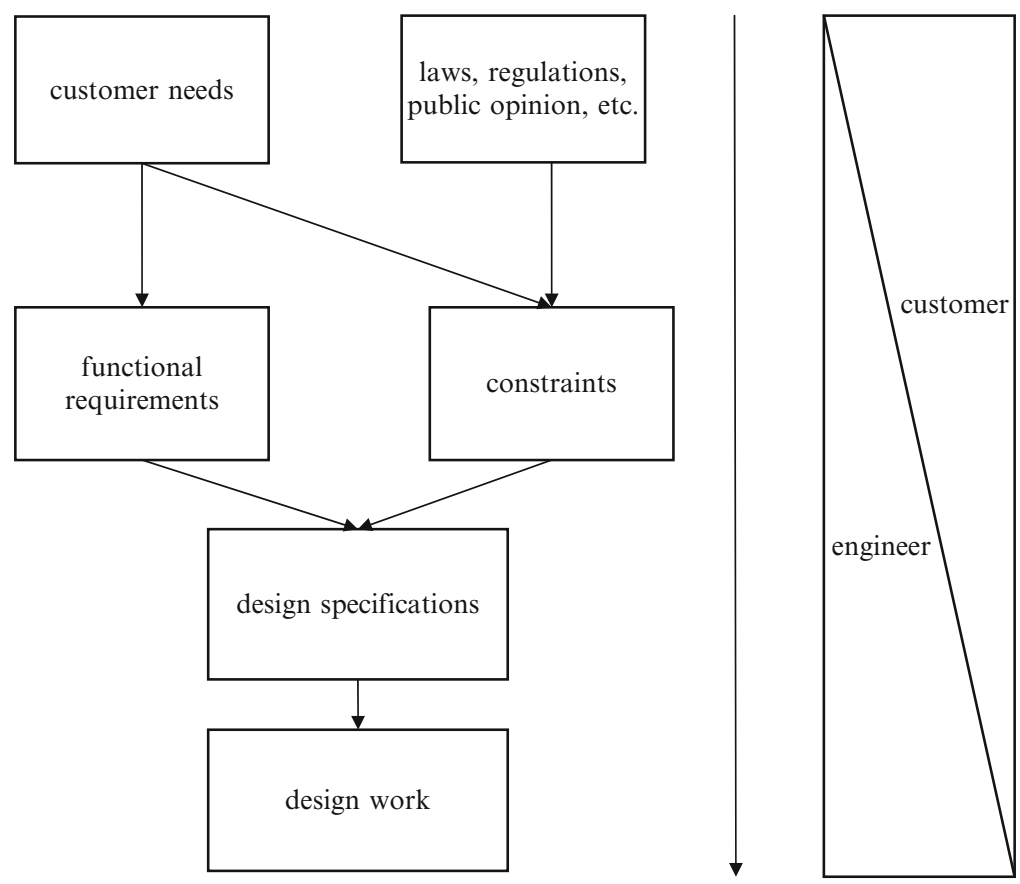

Fig. 6.1 The design process

are not. In large-scale engineering projects, constraints are often expressed both through formal documents, such as laws, regulations and environmental impact assessments, and informally, for example, through public opinion.

The distinction between functional requirements and constraints is not clear cut. ${ }^{6}$ Customer needs reflect a multitude of values that not only concern why but how a particular artefact should be developed. The reason why flood barriers are built is that coastal areas need to be protected. However, coastal protection is not an unambiguous goal. It can be achieved in ways that differ in environmental, economic and social respects. Few would agree to build a barrier that effectively solves the problem of flooding but at the same time causes irreversible or catastrophic environmental damage. In the standard model of engineering design, customer needs are expressed through two separate categories of norms: functional requirements and constraints. However, in terms of reflecting what the customer wants, functional requirements and constraints cannot be separated in this idealised way (de Vries 2009, p. 497) (see Fig. 6.1).

\footnotetext{
${ }^{6}$ Consider mobile phones and laptops. These have been developed because people need to be able to make calls and do work even when they are not physically in their offices. Being portable is thus a functional requirement; hence, the weight of a mobile phone or a laptop is a functional requirement that can be expressed in physical terms, for example, "x should not weigh more than". I am grateful to Sven Ove Hansson for pointing this out.
} 
Taking constraints into consideration, functional requirements are transformed into design specifications. Design specifications are structural descriptions of the artefact that specify measurable properties and behaviours. They are oriented towards the inner environment of the artefact - the artefact's internal structure - and say nothing about the function or why the artefact should be produced (Kroes 2009). The transformation process from functional requirements to design specifications is not a one-to-one projection; one functional requirement can be related to more than one physical feature, and vice versa (de Vries 2009, p. 498). If the set of design specifications adequately meets the functional requirements and the functional requirements are adequate operationalisations of the expressed customer needs, then the designed artefact is a reliable means to satisfy these needs.

Because engineering design problems are often "ill-defined", the design process is seldom linear. ${ }^{7}$ Functional requirements, design specifications and constraints often need to be readjusted as the design process proceeds. Some requirements, specifications or constraints may turn out to be superfluous; others may need to be added as knowledge is gained about the design problem. Therefore, as noted by Kroes (2009), engineering design is not so much a linear problem-solving activity starting from a fixed set of goals as a decision-making process that proceeds iteratively and through feedback loops. In the decision-making process, setting and fine tuning of goals is equally as important as finding the appropriate means of achieving goals.

Goals have a central normative function in engineering design. Customer needs transformed into functional requirements serve as the broad goals of a design project. They are used as a normative standard for a variety of decisions, perhaps most notably for the generation, evaluation and prioritisation of design solutions (specifications), but also for more practical decisions, for example, which competencies to involve in the project and how to allocate resources between different engineering teams. Design specifications, in turn, are used to direct action in a way that fulfils the functional requirements of an artefact and serve as normative standards for actual construction work.

The goals that engineers work with usually direct action both intertemporally (over time) and interpersonally (between different engineers or engineering teams). Intertemporally, goals enable engineers and engineering teams to plan their activities over time so that the goals are more easily achieved. Goals introduce a certain settledness about action and deliberation. The adoption of a goal means that

\footnotetext{
${ }^{7}$ According to Cross (2000, pp. 14-15), ill-defined design problems are characterised by the following:

1. The design problem is vaguely defined (i.e. goals are ambiguous, many constraints and criteria are unknown, and the problem context is poorly understood).

2. Any problem formulation may contain inconsistencies.

3. Formulations of the design problem are solution dependent (i.e. it is difficult to formulate the design problem without referring to a solution concept).

4. Searching for design solutions is a means of understanding the design problem.

5. There is no definitive solution to the design problem.
} 
there is commitment and that action will be taken to achieve it (McCann 1991, p. 206). This holds true in the engineering context too. Having decided on a particular goal, an engineer does not consider design solutions, plans and strategies that clearly work against the goal, at least until the goal itself has been reconsidered (cf. Levi 1986, p. 69ff.; Nozick 1993, p. 146). The goal functions as a "conduct controller" in that it (at least temporarily) narrows down the engineer's scope of future deliberations to a limited set of design solutions and provides a reason for considering some solutions but not others (cf. Bratman 1999; Schmidtz 1995, p. 7).

Engineering goals also facilitate coordination between different engineering teams. On the basis of an adopted goal, different engineers and engineering teams can beneficially plan and coordinate their work. The planning benefits gained in these situations also are derived from the stability of action and deliberation conveyed through goals. When an engineering team has adopted a particular goal, other engineering teams can, to some extent, predict what type of design solutions the first engineering team will search for, or at least what design solutions the team will not consider and adjust their own efforts accordingly (cf. Nozick 1993, p. 9).

\section{Designing the MOSE System}

The MOSE system (acronym for "Modulo Sperimentale Elettromeccanico", Experimental Electromechanical Module) is a set of mobile barriers designed to defend the City of Venice from high waters. ${ }^{8}$ The barriers, comprised of flap gates built into the seabeds of the Venice lagoon, are placed at the Lido, Malamocco and Chioggia inlets. When a tide exceeding $110 \mathrm{~cm}$ is forecast, the barriers are emptied of water by emission of compressed air. This causes the barriers to rise until they emerge above sea level and isolate the lagoon from the sea (Fig. 6.2). Depending on the severity of the situation, the MOSE system can close one inlet at a time or all inlets simultaneously. The barriers remain risen until the high tide has passed (approximately 4-5 h) and are then "folded away" into their housings at the bottom of the inlets. A navigation lock at the Malamocco inlet allows commercial ships to pass the barrier even when the mobile gates are raised. Small navigation locks are also placed at the Lido and Chioggia inlets.

The history of the MOSE project dates back to the early 1970s. After the dramatic floods of November 1966, the water issue in Venice began to attract increased attention. It became obvious that anticipatory action was needed to safeguard Venice from flooding. The problem was formally recognised in 1973 in Law No. 171/73, which declared the water issue in Venice to be "of priority national interest". Following the adoption of the law, the Ministry of Public Works issued a call for tender for the design and construction of high water defences for the Venice lagoon.

\footnotetext{
${ }^{8}$ Information about the MOSE project and other interventions to safeguard Venice and the Venice lagoon can be found on the Consorzio Venezia Nuova website (www.salve.it).
} 
Fig. 6.2 The MOSE floodgates in operation (www.salve.it)

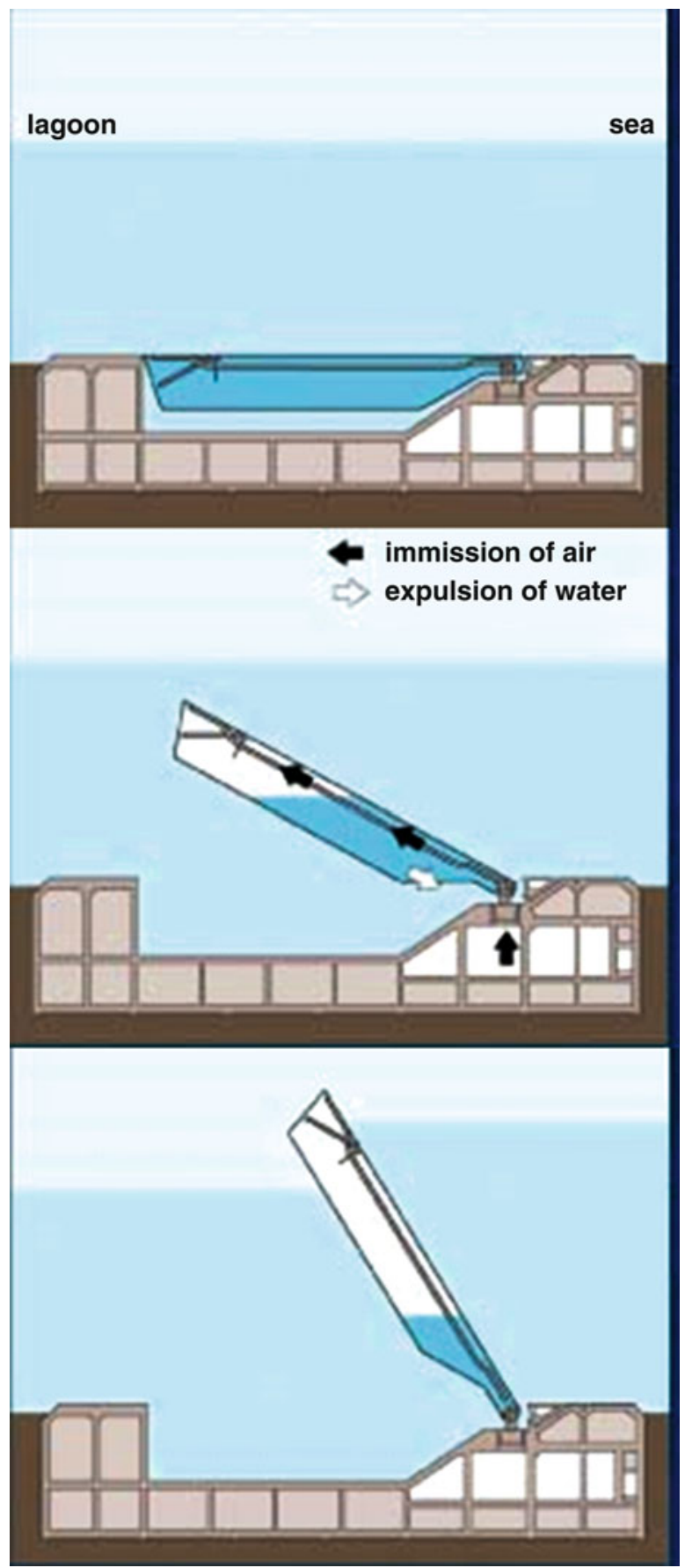


The tender, which was not awarded, resulted in five projects being used to draw up a preliminary design to protect Venice known as the General Feasibility Plan (the "Progettone"). In 1989, the Water Authority through the Consorzio Venezia Nuova - the Italian state concessionary for work to safeguard Venice - presented a complex proposal of measures to protect the city from flooding, including the conceptual design of a mobile barrier named the "Riequilibrio E Ambiente", REA.

In the REA project, different hypotheses were tested to find the best defence system for Venice. In particular, three different strategies were considered (www. salve.it):

1. Protection of built-up areas in the lagoon with local defence measures, for example, raising of quaysides, raising of buildings and raising of the land by deep injections

2. Modification of the physical structure of the lagoon, for example, reconstruction of the raised edges along lagoon channels and filling in of the Canale Petroli oil tanker channel

3. Permanent or temporary measures at the lagoon inlets, for example, permanent narrowing with transverse groynes and temporary closure of the lagoon inlets

A system of mobile barriers, placed at the lagoon inlets in combination with local raising of quaysides, was considered the most strategic solution considering the environmental (lagoon ecology, morphology, chemistry, etc.) and socio-economic (avoidance of interference with activities in the Venice ports, etc.) constraints and criteria involved (Spencer et al. 2005, p. 143).

To find the best mobile barriers, the designers then analysed a number of flood-defence systems already in place, including the Maesland barrier (Rotterdam) and the Thames barrier (London). Six different conceptual designs were considered (www.salve.it):

1. Barriers with intermediate piles to install the operating mechanisms, for example, sluice gate, butterfly gate and sector gate

2. Barriers with operating mechanisms in the seabed, for example, oscillating buoyancy flap gate, drum gate and bear-trap gate

3. Barriers using innovative materials, for example, cushion gate and floating gate with sail

4. Barriers using innovative systems

5. Barriers with continuous elements along half the inlet channel, for example, floating gate with hinged structure for installation

6. Barrier with deep foundation structures

The decision was that a barrier with operating mechanisms in the seabed - in this case an oscillating buoyancy flap gate - would be the best solution for the Venice lagoon given the constraints and criteria involved.

In 1992, after extensive experimentation, the preliminary design for the mobile barriers was completed. A negative response to the barrier design by the Ministry of the Environment's Environmental Assessment Commission in 1998 resulted in an update and further developments. In 2002, the final design of the MOSE system was 
presented by the Consorzio Venezia Nuova. ${ }^{9}$ In April 2003, the formal decision to build the barrier was taken by the Committee for Planning, Coordination and Control ("Comitatone") in Rome.

Evident in the MOSE project is that engineering design is essentially an iterative decision-making process that often starts out from an "ill-structured" problem and operates under a wide variety of constraints. It became clear that the initial design remit was ill-structured as the Public Works Administration evaluated the proposals presented in response to the 1975 call for tender. As the evaluation process continued, it became obvious that none of the proposals could be selected. By the time the evaluation process came to an end, the design problem was revealed in its full complexity. Before a solution satisfying the manifold requirements, constraints and criteria involved could even be suggested, in-depth, multi-sectoral and multidisciplinary knowledge and information about the situation in the lagoon was needed (www.salve.it).

The MOSE design process operated under a wide variety of constraints; this is evidenced in the many documents issued by local and national authorities during the process. For example, in Vote no. 209 of 1982, the Higher Council of Public Works formulated a set of instructions and recommendations (later incorporated into Law 798/84) that had to be taken into consideration. The instructions emphasised the importance for any design project of "[s]afeguarding objectives and characteristics inherent in the unity and physical continuity of the lagoon" (www.salve.it). The instructions also highlighted the need to proceed through an iterative decision-making process, that is, gradually and experimentally, and in close collaboration with research.

\section{Precision}

Engineering design goals need to be precise, not only to guide the engineer(s) responsible for the implementation of the goals but also to constitute useful criteria on the basis of which proposed design solutions (conceptual designs, prototypes, etc.) can be assessed and evaluated. Only when engineering design goals are precise "[c]an one test the design against the requirements and determine whether or not the former satisfies the latter" (Maimon and Braha 1996, p. 146).

There are different types and degrees of goal specification. A goal is directionally precise if it specifies a direction for the engineer's work - this is a straightforward minimum requirement for goal specification. A goal has completive precision if it specifies not only in what direction the engineer should go to reach the goal but also to what extent the goal should be realised. For example, the goal "After closing the barriers, Venice should suffer much less risk of flooding" has directional precision, whereas the goal "After closing the barriers, the rate of rise of the lagoon water level

\footnotetext{
${ }^{9}$ Construction details of the barrier are described in Eprim (2005).
} 
due to inflow through the gaps should not exceed $3 \mathrm{~mm} \mathrm{~h}-1$ " has directional and completive precision. ${ }^{10}$ Finally, an engineering design goal is temporally precise if it specifies a point in time when the goal should be achieved.

Actual degrees of goal specification vary between the different levels of the design process. As a general rule, the "further down" in the transformation process from customer needs to design specifications, the more precise goals tend to be. Customer needs usually have only directional precision, at least in the initial stage. This is part of the reason why engineering design problems are often "ill-defined." 11 Sometimes, the customer knows what type of artefact is wanted but has little idea of possible designs. At other times, the need is much vaguer and is expressed simply as a problem that must be solved (Cross 2000, p. 61). This was, for example, the case in the MOSE project, where the starting point for the engineers' work was an identified problem to be solved but with little or no indication of what sort of solution would be approved in the end.

At the design-specification level, the goals that engineers work with are usually well defined. Often, the goals are formulated in quantitative terms that specify acceptable limits concerning size, weight, pressure, durability, temperature, noise, etc. In large-scale engineering projects, there are a great number of design specifications. Work is usually divided between different engineering teams, and separate sets of design specifications are made for different parts of the artefact. In the MOSE project, these included the foundation caissons, the gates, the electrical services, the preparatory works, etc.

For an engineer, goal imprecision can be a problem at all stages in the design process. Vaguely expressed customer needs are difficult to operationalise into functional requirements, and vague functional requirements are difficult to transform into adequate design specifications. In actual design practice, imprecision often creates difficulties in the problem-definition phase, that is, when customer needs are transformed into functional requirements. There is a necessity to obtain a satisfactory definition of the problem. However, because customers and engineers express themselves differently, problem definition is a difficult task. A word used by the customer to express a need or describe a particular problem may have a different meaning for the engineer, or may not be precise enough to guide the engineer's design work (de Vries 2009, p. 495). To arrive at a common definition, the transformation from customer needs to functional requirements often has to proceed iteratively and through negotiation.

Engineering goals that are broad or vague are generally problematic from an action-guiding standpoint since they leave the engineer with little idea of what to aim for. Vague customer needs or functional requirements can lead to inappropriate solutions being considered and then discarded when it is found that they do not fall within the range of what is considered acceptable (Cross 2000, p. 91). This can make the design process unnecessarily expensive. On the other hand, well-defined

\footnotetext{
${ }^{10}$ The last goal formulation is taken from Eprim (2005, p. 257).

${ }^{11}$ See footnote 7.
} 
engineering goals can also be problematic. Detailed customer needs have the potential to hamper the creativity of the engineer and lead to designs that are inefficient from a multi-goal perspective. When the problem definition is narrow, the engineer may overlook unusual or unconventional solutions that could otherwise help to solve the problem (Dieter 1991, p. 7). It is therefore preferable to formulate the overall goals of an engineering project as broadly as possible at first and then narrow them down at a later date if necessary (Cross 2000, p. 78).

\section{Evaluability}

To guide action, engineering design goals must not only be precise. Goals should also be evaluable, that is, it should be possible to measure degrees of goal achievement. Only when goals (and criteria) are evaluable is it possible to assess the adequacy of different design proposals before deciding on a final version for manufacture (Cross 2000, p. 6). Similarly, final design solutions can only be properly assessed when the goals and criteria against which the solutions are evaluated are transparent. Furthermore, evaluability guarantees that accountability for insufficient goal achievement can be established, at least in principle. This is particularly important in large-scale engineering projects with a number of engineering teams.

Successful goal evaluation presupposes that the intended end state is adequately specified. This requirement is basically met when engineering goals are precise as previously described. However, since evaluation is an assessment of the outcome in light of adopted goals and criteria, successful goal evaluation also presupposes that it is possible to establish how well the engineer's design solution aligns with the intended end state (Edvardsson and Hansson 2005, p. 353). In other words, degrees of partial attainment must be distinguishable.

To successfully measure goal achievement, at least two things must be decided: (1) what indicators should be used to signal goal achievement and (2) what levels of attainment (for these indicators) should be used to signal sufficient goal achievement. If the goal is to design a barrier that protects Venice from floods while permitting a functional lagoon ecosystem to thrive, for example, different sets of environmental indicators could be used to signal goal achievement. These include levels of erosion/ sedimentation in the lagoon, levels of toxic substances, occurrence of mercury cycling, presence of pathogenic microbial communities in water or sediment and occurrence of salt marsh colonisation (Deheyn and Shaffer 2007, p. 208). For each of these, it must then be decided what levels signal satisfactory goal achievement. These choices are not value neutral. Deciding on a particular set of indicators or level of attainment indicates which aspects of the goal are most important.

Evaluability is usually not a problem at the design-specification level when goals are quantitative and well defined. Given that there are reliable measurement instruments and methods available to test a design solution, assessing goal achievement is for the most part a straightforward activity. However, assessing goal achievement at "higher levels" in the engineering design process is challenging. Two factors 
complicate the evaluation of design solutions. First, goals at "higher levels" in the engineering design process are sometimes vague, abstract or value-laden. To save Venice from floods while permitting a functional lagoon ecosystem to thrive is an example of an abstract and value-laden goal since there is no absolute definition of what constitutes a "functional lagoon ecosystem". When abstract or value-laden goals are operationalised into quantitative design specifications, indicators and criteria, there is always a risk that the engineer could lose sight of the overarching goals. The various operationalisations of the overarching goals instead become the "real goals" of the engineer's project.

Second, design solutions generally have to be evaluated against multiple goals or criteria. Different design solutions advance different goals to different extents. For example, one particular type of flood-barrier design could better satisfy environmental considerations compared with other designs while at the same time be more troublesome from the viewpoint of safety and commercial activity. An important part of the evaluation process is weighing these different goals, or criteria, against one another. There is a question as to whether any rational method can be employed to find a design solution that is optimal from a multi-criteria perspective. Philosophers of technology have argued against the existence of such a rational method (e.g. Franssen and Bucciarelli 2004; Franssen 2005). Drawing on insights gained in social choice theory, they argue that since no general rational solution method can be found for multi-criteria decision problems of this kind, it is problematic to talk about designs as optimal solutions. Instead, engineering design should be understood as a social process in which different goals and interests are negotiated and in which bargaining and strategic thinking are recurrent phenomena (Franssen et al. 2009).

\section{Approachability}

That goals should be attainable, or at least possible to reach to a meaningful degree, is a criterion often referred to in discussions of goal-setting rationality (Edvardsson Björnberg 2008). For example, in relation to scientific goals, Laudan (1984) has argued that only those goals that satisfy a particular set of conditions - namely, those goals that are not demonstrably, semantically or epistemically utopian should be accepted as valid goals. His argument is that unrealistic goals should be rejected because it is unreasonable to adopt goals that are of no use in the selection of means towards their realisation. The normative criterion of approachability has also attracted some attention in engineering design literature. In actual design practice, the criterion is explicitly taken into consideration via feasibility studies (Hughes 2009). Feasibility studies are conducted - usually on conceptual designs in order to validate the (technical, economical, legal, etc.) feasibility of a proposed solution and to make sure that the design that is eventually chosen satisfies customer needs with the available resources (Ertas and Jones 1996, p. 11).

Engineering goals can be divided into goals that represent demands and goals that represent wishes or wants (Pahl and Breitz 1996, p. 131). Demands are minimum 
requirements that must be met. For obvious reasons, such goals need to be fully attainable. Wants are aspirational targets that the customer or designer would like to meet as far as possible and are therefore worth incorporating into the design project (Cross 2000, p. 94). Ideally these targets should be possible to reach to some degree, but do not have to be fully attainable.

The degree to which an engineering design goal is attainable is often determined by the relations that exist between the goal and other goals. Some design goals may be realistic in that they are possible to attain or approach but only at very high cost. Such goals are only realistic in a weak sense. In actual design practice, degrees of attainability often relate to the financial resources available. For example, in floodbarrier design, it might be possible to reconcile all effectiveness, safety and environmental considerations through some innovative solution, but this would most likely come at an extreme and indefensible cost.

How ambitious should the goals set by engineers be? In software engineering, it has been argued that unrealistic goals, such as designing data programmes entirely free of bugs, should not be adopted since overly strong responsibility for goal failure would then accrue to the engineers who design the programmes (Stieb 2008; see also Miller 2008; Huff 2008). From a moral viewpoint, accepting such responsibility goes beyond what can reasonably be expected from a software engineer.

From a rationality viewpoint, however, there is evidence to support the argument that engineering goals should be relatively challenging. Psychological research has found that there is a positive correlation between the degree of difficulty pertaining to a goal and the level of performance displayed by the agent as they try to reach the goal. ${ }^{12}$ The relationship is sometimes referred to as the "goal-difficulty function". ${ }^{13}$ In simple terms, the goal-difficulty function implies that the more challenging a goal, the greater effort the agent is likely to make in order to reach the goal. This is believed to hold true at least up to a certain level of goal difficulty. For goals that are perceived to be very ambitious or challenging, though, research has shown that the agent may lose motivation to reach the goal (Stedry and Kay 1966). The latter argument is that when an unrealistic goal is used as a referent to which the agent's performance is compared, the discrepancy between the goal and the agent's actual performance will be so great that the goal does not, as with realistic goals, create corrective motivation to change the agent's behaviour (Campion and Lord 1982).

Based on the former evidence, it could be argued that challenging rather than easily attained goals should be set since this would likely lead to higher levels of goal achievement, that is, better designs. Setting ambitious goals, or sets of goals that are difficult to co-achieve, could motivate engineers to present creative and unexpected solutions that would otherwise not have been discovered. In other words,

\footnotetext{
${ }^{12}$ However, to the author's knowledge, no such research has been undertaken on engineering goals.

${ }^{13}$ A comprehensive meta-study of the empirical research on the goal-difficulty function can be found in Locke and Latham (1990). See also Locke and Latham (2002) for a shorter but more recent discussion.
} 
highly demanding engineering goals or ideals could be an effective tool for "approximating the good" (Huff 2008, p. 243).

However, because engineering design problems are often ill-defined, it can be difficult to set sufficiently challenging engineering goals. When there is no definitive problem formulation at the outset, complexities and inconsistencies can cause the initial problem to be poorly understood, as in the MOSE project. Therefore, engineering goals have to be set on a somewhat intuitive basis and then be subsequently adjusted as more knowledge is gained. This is particularly the case in large-scale engineering where an often complex combination of factors determines the success or failure of a particular design.

\section{Consistency}

To successfully guide action, engineering goals also need to be consistent. A set of goals is consistent when measures can (realistically) be taken to approach one goal without making it more difficult to achieve the other goals in the set. Conflicting goals guide action in opposite directions, making it more difficult to coordinate action effectively among engineers and engineering teams. In the absence of clear goal prioritisation and a continuous dialogue between the design teams involved, the design project can become costly and time-consuming.

However, though generally problematic from a planning perspective, it may not be irrational to adopt conflicting goals. There are several reasons why this holds true in an engineering design context. Firstly, it can be difficult to know in advance the extent to which a set of engineering goals or requirements are consistent. Consistent goals that are adopted at one point in the design process may conflict when more detailed information about feasibility becomes available or when conditions external to the goals change - constraints may be added, environmental conditions may change, the financial situation may deteriorate, etc. (Edvardsson Björnberg 2009). For example, the on-going global financial crisis could make some of the more attractive and expensive design solutions in the Venice Dams case impossible to implement in practice. Conversely, goals that were previously in conflict can become more consistent as finances improve or new design solutions (materials, processes, etc.) are discovered.

Second, to create sets of goals that are free of conflict, engineers would have to systematically avoid goals that represent any real challenge or commitment since there is always a risk of conflict. ${ }^{14}$ This is not desirable, as noted, since working towards goals that are difficult to reconcile can spur innovative reflection, discussion

\footnotetext{
${ }^{14}$ An analogous argument has been made by Hansson (1998), who argues against the position that a person's moral values always need to be consistent. The reason for this is that strategies that reduce the incidence of moral dilemmas tend to have side effects that are not worth the price. For example, to avoid dilemmas as much as possible, a person would have to systematically avoid commitments to other people since virtually any such commitment increases the risk that they will later be caught in a dilemma.
} 
and action (see Sect. 6). An example is the attempt to reconcile the goal of effectively protecting Venice against flooding with stated goals such as preserving the "unity and physical continuity of the lagoon". Although difficult, such challenges have allowed design practice to evolve successfully.

Third, in engineering practice, goal conflicts are more or less considered a given. In large-scale engineering design, safety and economic requirements could conflict, as could economic with environmental or ethical requirements. There is no easy way to avoid this; negotiating requirements and finding solutions that reconcile conflicting goals are considered integral to engineering design.

Different methods can be used to solve or negotiate engineering goal conflicts; however, these are not discussed at any length in this chapter. ${ }^{15}$ There are basically two levels at which such goal conflicts can be dealt with. Goal conflicts can be approached in the problem definition phase, as customer needs are transformed into functional requirements. In practice, this means that adjustments and compromises are made before the goals of the design project are set (cf. Rosencrantz et al. 2007). The other approach is for goals to be set and then negotiated at "lower levels" in the design process. As a general rule, the "further down" in the design process the negotiation takes place, the greater influence engineers usually have over the goals and value trade-offs involved (see Fig. 6.1).

\section{Concluding Remarks}

This chapter argues that engineering goals can be meaningfully evaluated in terms of rationality. Four criteria - precision, evaluability, approachability and consistency - have been analysed in relation to the MOSE system engineering project in Venice. The argument has been that although all criteria are relevant in a goal-setting context, the normative strength of the criteria varies depending on which part of the engineering process is under consideration. As a general rule, the "further down" one is in the transformation process from customer needs to design specifications, the more important it is that the goals with which engineers work satisfy the identified goal criteria.

It should be noted that the analysis in this chapter has limited scope and that further research is needed to establish the conditions for effective goal setting in engineering design. In this chapter, only four goal criteria have been analysed. In addition, there may be a need to identify other criteria in order for an engineering goal, or a set of engineering goals, to be rational. Examples of such criteria could be that engineering goals are understandable and communicable (which is not equivalent to being precise) or that sets of engineering goals consist of a limited number of goals.

Furthermore, for an engineering goal to be considered rational, it may not be sufficient to analyse the structural properties as has been done in this chapter. There

\footnotetext{
${ }^{15}$ For a description of some of these methods, see Chapter 10 in Cross (2000) and de Vries (2009).
} 
should also be an analysis of the goal-setting process, for example, to determine if goals were set in accordance with established design methodologies or if the arguments that were used in this process were based on sound scientific or technological knowledge.

Finally, there is the argument that to function well, it is not sufficient that engineering goals only meet the goal criteria presented in this chapter; the goals must also operate in a "supportive" organisational context. This could, for example, mean that there is a well-defined system of monitoring, evaluation and feedback in force at all stages in the design process to ensure that knowledge and experience can be shared among the project engineers. This, in turn, presupposes that there are adequate channels of communication among different engineering teams and between the design project's leadership and the engineers responsible for day-to-day functions.

Acknowledgments I would like to thank Professor Marc de Vries, Professor Sven Ove Hansson and Professor Peter Kroes for their valuable comments and suggestions. I would also like to thank the participants at Track 7: Philosophy of Engineering and Design at the 2011 Society for Philosophy and Technology (SPT) conference in Denton, Texas, for their comments. Any remaining errors, if any, are mine.

\section{References}

Baumslag, D. 1998. Choosing scientific goals: The need for a normative approach. Studies in History and Philosophy of Science 29(1): 81-96.

Bratman, M.E. 1999. Intention, plans, and practical reason. Stanford: CSLI Publications.

Bucciarelli, L.L. 1994. Designing engineers. Cambridge, MA/London: The MIT Press.

Campion, M.A., and R.G. Lord. 1982. A control systems conceptualization of the goal-setting and changing process. Organizational Behavior and Human Performance 30(2): 265-287.

Cíntora, A. 1999. Critical comments on Laudan's theory of scientific aims. Sorites 10: 19-38.

Cross, N. 2000. Engineering design methods: Strategies for product design, 3rd ed. Chichester: Wiley.

de Vries, M.J. 2009. Translating customer requirements into technical specifications. In Handbook of the philosophy of science. Vol. 9: Philosophy of technology and engineering sciences, ed. A. Meijers, 489-512. Amsterdam: Elsevier.

Deheyn, D.D., and L.R. Shaffer. 2007. Saving Venice: Engineering and ecology in the Venice lagoon. Technology in Society 29: 205-213.

Dieter, G.E. 1991. Engineering Design: A Materials and Processing Approach, 2nd ed. New York: McGraw-Hill.

Edvardsson Björnberg, K. 2008. Utopian goals: Four objections and a cautious defence. Philosophy in the Contemporary World 15(1): 139-154.

Edvardsson Björnberg, K. 2009. What relations can hold among goals, and why does it matter? Crítica Revista Hispanoamericana de Filosofía 41(121): 47-66.

Edvardsson, K., and S.O. Hansson. 2005. When is a goal rational? Social Choice and Welfare 24(2): 343-361.

Eprim, Y. 2005. Venice mobile barriers project: Barrier caissons construction details. In Flooding and environmental challenges for Venice and its Lagoon: State of knowledge, ed. C.A. Fletcher and T. Spencer, 257-262. Cambridge: Cambridge University Press.

Ertas, A., and J.C. Jones. 1996. The engineering design process, 2nd ed. Chichester: Wiley.

Franssen, M. 2005. Arrow's theorem, multi-criteria decision problems and multi-attribute preferences in engineering design. Research in Engineering Design 16(1-2): 42-56. 
Franssen, M., and L.L. Bucciarelli. 2004. On rationality in engineering design. Journal of Mechanical Design 126(6): 945-949.

Franssen, M., Lokhorst, G.-J., and I. van de Poel. 2009. Philosophy of technology. In The stanford encyclopedia of philosophy, ed. Edward N. Zalta, plato.stanford.edu/entries/technology/. Publisher is: The Metaphysics Research Lab, Center for the Study of Language and Information, Stanford University, Stanford, CA 94305-4115.

Hansson, S.O. 1998. Should we avoid moral dilemmas? The Journal of Value Inquiry 32(3): 407-416.

Huff, C. 2008. It is not all straw, but it can catch fire: In defense of impossible ideals in computing. Science and Engineering Ethics 14: 241-244.

Hughes, J. 2009. Practical reasoning and engineering. In Handbook of the philosophy of science. Vol. 9: Philosophy of technology and engineering sciences, ed. A. Meijers, 375-402. Amsterdam: Elsevier.

Iranzo, V. 1995. Epistemic values in science. Sorites 1: 81-95.

Kroes, P. 2009. Foundational issues of engineering design. In Handbook of the philosophy of science. Vol. 9: Philosophy of technology and engineering sciences, ed. A. Meijers, 513-541. Amsterdam: Elsevier.

Kroes, P., M. Franssen, and L. Bucciarelli. 2009. Rationality in design. In Handbook of the philosophy of science. Vol. 9: Philosophy of technology and engineering sciences, ed. A. Meijers, 565-600. Amsterdam: Elsevier.

Laudan, L. 1984. Science and values: The aims of science and their role in scientific debate. Berkeley: University of California Press.

Levi, I. 1986. Hard choices: Decision making under unresolved conflict. Cambridge: Cambridge University Press.

Locke, E.A., and G.P. Latham. 1990. A theory of goal setting and task performance. Englewood Cliffs: Prentice-Hall.

Locke, E.A., and G.P. Latham. 2002. Building a practically useful theory of goal setting and task motivation: A 35-year odyssey. American Psychologist 57(9): 705-717.

Maimon, O., and D. Braha. 1996. On the complexity of the design synthesis problem. IEEE Transactions on Systems, Man, and Cybernetics - Part A: Systems and Humans 26(1): 142-151.

McCann, H.J. 1991. Settled objectives and rational constraints. American Philosophical Quarterly 28: 25-36. (Reprinted in Mele, A.R. (ed.). 1997. The philosophy of action, 204-222. Oxford: Oxford University Press.)

Miller, K.W. 2008. Critiquing a critique. A comment on "A critique of positive responsibility in computing". Science and Engineering Ethics 14(2): 245-249.

Nozick, R. 1993. The nature of rationality. Princeton: Princeton University Press.

Pahl, G., and W. Breitz. 1996. Engineering design: A systematic approach, 2nd ed. Berlin: Springer.

Rosencrantz, H., K. Edvardsson, and S.O. Hansson. 2007. Vision zero - Is it irrational? Transportation Research Part A: Policy and Practice 41(6): 559-567.

Schmidtz, D. 1995. Rational choice and moral agency. Princeton: Princeton University Press.

Spencer, T., P.M. Guthrie, J. Da Mosto, and C.A. Fletcher. 2005. Introduction: Large-scale engineering solutions to storm surge flooding. In Flooding and environmental challenges for Venice and its Lagoon: State of knowledge, ed. C.A. Fletcher and T. Spencer, 241-244. Cambridge: Cambridge University Press.

Stedry, A.C., and E. Kay. 1966. The effects of goal difficulty on performance: A field experiment. Behavioural Science 11(6): 459-470.

Stieb, J.A. 2008. A critique of positive responsibility in computing. Science and Engineering Ethics 14(2): 219-233. 